\title{
Simultaneous identification and correction of systematic error in bioenergetics models: demonstration with a white crappie (Pomoxis annularis) model
}

\author{
Przemyslaw G. Bajer, Robert S. Hayward, Gregory W. Whitledge, and \\ Richard D. Zweifel
}

\begin{abstract}
Recent evidence indicates that important systematic error exists in many fish bioenergetics models (BEMs). An approach for identifying and correcting this error is demonstrated with a white crappie (Pomoxis annularis) BEM. Model-predicted trajectories of growth and cumulative consumption for 39 individual white crappie obtained from six 60 -day laboratory experiments diverged from observed values by up to $42.5 \%$ and $227 \%$, respectively, indicating systematic error in the BEM. To evaluate correlates of the systematic error, model prediction errors were regressed against three major input/output variables of BEMs that were covered by the laboratory experiments: fish body weight (80$341 \mathrm{~g})$, temperature $\left(23-30{ }^{\circ} \mathrm{C}\right)$, and consumption level $(0.5 \%-6.2 \%$ daily). Consumption level explained $>80 \%$ of the prediction error for growth and consumption. Two multiple regression equations containing body weight, temperature, and consumption variables were developed to estimate growth prediction error $\left(R^{2}=0.96\right)$ and consumption prediction error $\left(R^{2}=0.86\right)$, and incorporated into the white crappie BEM to correct its predictions. Cross-validation indicated that growth and consumption prediction error was reduced 2- to 4-fold by correction. Given recent evidence of widespread systematic error and increasing application rates of BEMs, the efficient error-identification and -correction approach described appears broadly applicable and timely.
\end{abstract}

Résumé : Des études récentes indiquent qu'il existe une erreur systématique importante dans plusieurs modèles bioénergétiques (BEM)de poissons. Nous faisons la démonstration d'une méthode pour identifier et corriger cette erreur à l'aide d'un BEM de la marigabe blanche (Pomoxis annularis). Les trajectoires de croissance et de consommation cumulative de 39 individus obtenues dans six expériences de 60 jours diffèrent des valeurs observées par autant que $42,5 \%$ et $227 \%$, respectivement; il y a donc une erreur systématique dans le BEM. Afin d'évaluer les facteurs qui sont en corrélation avec l'erreur systématique, nous avons fait des régressions entre les erreurs de prédiction du modèle et trois variables d'entrée ou de sortie des BEM obtenues dans les expériences de laboratoire, soit la masse corporelle des poissons $(80-341 \mathrm{~g})$, la température $\left(23-30{ }^{\circ} \mathrm{C}\right)$ et le niveau de consommation $(0,5-6,2 \%$ par jour). Le niveau de consommation explique $>80 \%$ de l'erreur de prédiction de la croissance et de la consommation. Nous avons mis au point deux équations de régression multiple qui incluent comme variables la masse corporelle, la température et la consommation, afin d'estimer l'erreur de prédiction de la croissance $\left(R^{2}=0,96\right)$ et de la consommation $\left(R^{2}=0,86\right)$; nous les avons incorporées au BEM de la marigane blanche pour corriger les prédictions. Une validation croisée indique que la correction réduit par un facteur de 2-4 les erreurs dans les prédictions de croissance et de consommation. Étant donné la démonstration récente d'une erreur systématique générale dans les BEM et compte tenu de l'utilisation de plus en plus fréquente des BEM, la méthode efficace d'identification et de correction des erreurs que nous décrivons arrive à point et semble devoir s'appliquer sur une grande échelle.

[Traduit par la Rédaction]

\section{Introduction}

Fish bioenergetics models (BEMs) have been developed for a substantial and increasing number of species and life stages (Hewett and Johnson 1987; Hanson et al. 1997) and evidence indicates rapidly increasing application rates of these models. A primary literature search (Biological Abstracts) revealed that of a total of 114 studies that used BEMs from 1980 to 2003, more than two-thirds were published in the last 7 years of the 23-year period. We suspect that numerous additional

Received 6 August 2003. Accepted 27 July 2004. Published on the NRC Research Press Web site at http://cjfas.nrc.ca on 26 January 2005.

J17693

P.G. Bajer, R.S. Hayward, ${ }^{1}$ G.W. Whitledge, and R.D. Zweifel. ${ }^{2}$ Department of Fisheries and Wildlife Sciences, 302 AnheuserBusch Natural Resources Building, University of Missouri-Columbia, Columbia, MO 65211-7240, USA.

${ }^{1}$ Corresponding author (e-mail: HaywardR@missouri.edu).

${ }^{2}$ Present address: Department of Wildlife and Fish Science, South Dakota State University, Brookings, SD 57007, USA. 
Table 1. Applied ration levels, temperatures, body-weight ranges, and total and subperiod durations for six laboratory experiments in which consumption and growth rates for white crappie (Pomoxis annularis) were determined.

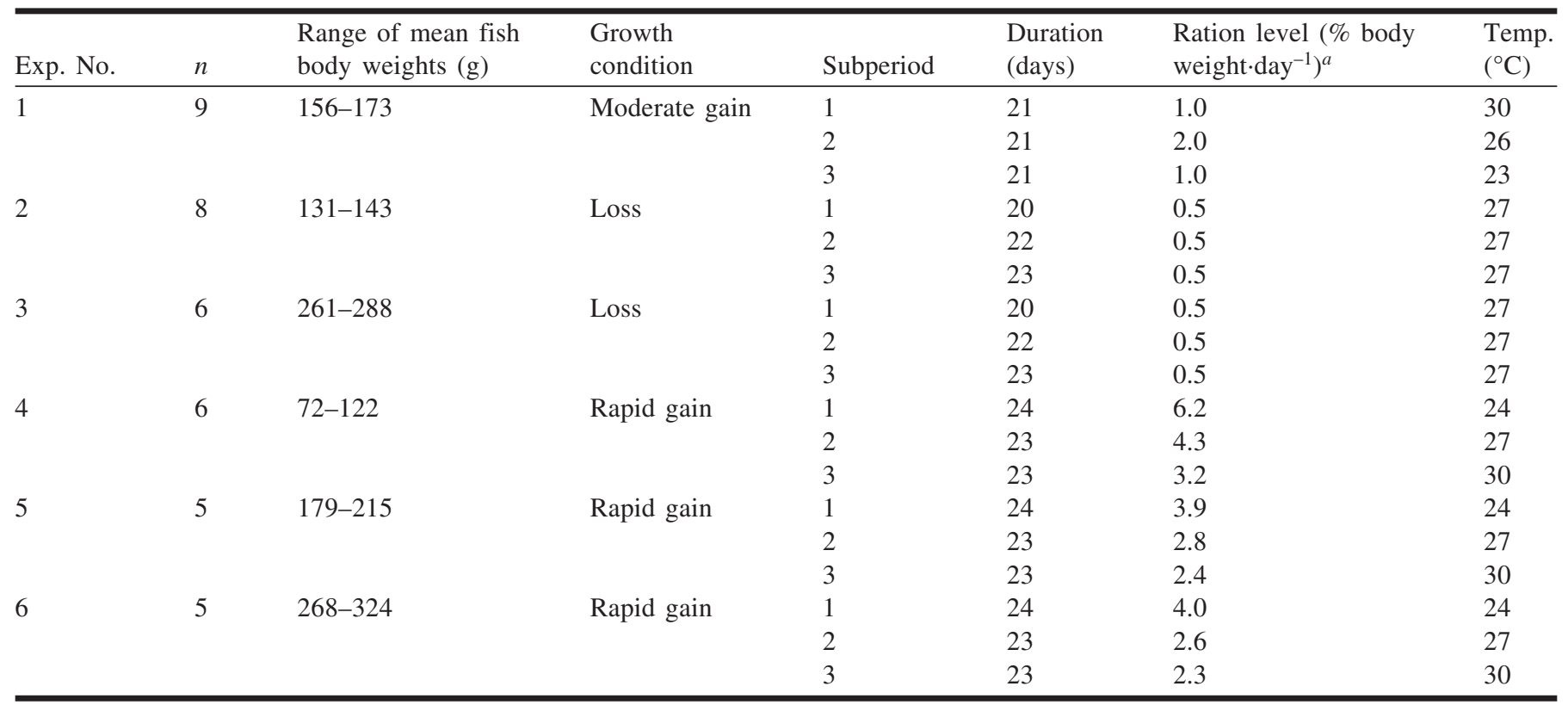

Note: Applied conditions produced weight loss or moderate or rapid weight gain. Experiments 2 and 3 involved constant conditions of applied ration level and temperature across the three subperiods, while all other experiments involved distinct combinations of ration level and temperature within subperiods ( $n$ is the number of fish in each experiment).

${ }^{a}$ Fish were fed rations ad libitum during subperiods 1,2 , and 3 of experiments 4-6.

BEM applications were performed during 1980-2003 at a similar increasing rate, to facilitate decisions relating to fisheries management, aquatic ecology, and aquaculture, but were either not published or placed in the grey literature.

Recent studies have identified the presence of strong systematic error in BEMs (Madenjian and O'Connor 1999; Bajer et al. 2003), while another study has shown this type of error to be widespread among these models and to have potentially important consequences relating to predictions of consumption and growth rates (Bajer et al. 2004). That many BEMs apparently contain important systematic error, while being applied at increasing rates, heightens the need for actions to improve them.

Bajer et al. (2003), and to a further extent Bajer et al. (2004), discuss likely sources of the systematic error found within BEMs. These insights should facilitate efforts to fundamentally improve BEMs by identifying specific internal subequations that warrant reevaluation and possible improvement. However, fundamental improvement of BEMs will require substantial research efforts without the guarantee of success. The present study introduces an efficient alternative approach for reducing systematic error in BEMs, leading to improved accuracy of growth and consumption predictions. Through this approach, systematic error is both identified and corrected from a single set of laboratory data that can be developed with reasonable effort. The approach that we describe appears valuable and timely, as it could expedite needed improvements to these frequently used models.

\section{Methods}

Laboratory data sets

White crappie (Pomoxis annularis) were grown in six lab- oratory experiments each of approximately 60 days' duration to provide test data for evaluating the accuracy of growth and consumption predictions by means of a modified version of the white crappie BEM of Zweifel (2000). Collectively, the experiments permitted model evaluation under conditions where white crappie of various sizes were gaining weight (experiments 1, 4, 5, and 6) as well as losing weight (experiments 2 and 3 ) at temperatures from just below the growth optimum $\left(23{ }^{\circ} \mathrm{C}\right)$ to incipient upper lethal levels for older juvenile and adult fish $\left(30{ }^{\circ} \mathrm{C}\right)$. Model performance under these higher temperatures was of particular interest because of plans to eventually use it to evaluate white crappie growth responses under summer thermal conditions for wide ranges of consumption level. Fish were held individually in each experiment and each fish's daily consumption was directly determined under known temperature. Changes in fish body weight were determined every 720 days. Fish weights in experiments ranged from about 70 to $325 \mathrm{~g}$ and applied ration levels ranged from $0.5 \%$ (submaintenance feeding) to about $6 \%$ of body weight per day (ad libitum feeding).

Experiment 1 consisted of three successive 21-day subperiods, each with distinct combinations of constant temperature and ration level (Table 1). Planned temperature changes during this experiment were made at rates not exceeding $1{ }^{\circ} \mathrm{C} \cdot \mathrm{day}^{-1}$, while changes in ration level between subperiods were performed immediately. Experiments 2 and 3 each involved continuous submaintenance feeding at $27^{\circ} \mathrm{C}$; the two experiments differed in the sizes of fish that were tested (Table 1). Experiments 4-6 also consisted of three subperiods, each offering distinct growth conditions. In each of these experiments, fish were provided rations ad libitum, while the temperature was incremented from 24 to 27 to $30{ }^{\circ} \mathrm{C}$ over 
the three 15-day subperiods. Subperiods were separated by 10 days for acclimation to temperature changes; during these 10-day periods fish were fed at half-maximum rations, achieved by feeding ad libitum every other day. The three experiments varied primarily in the sizes of fish that were grown (Table 1). All laboratory experiments were conducted between June and August during 1997, 2000, and 2002. All white crappie used in experiments were collected from Little Dixie Lake, Callaway County, Missouri. No fish was used in more than one experiment.

White crappie were acclimated to experimental conditions for at least 1 month prior to each experiment. During the first 2 weeks of acclimation, fish were provided fathead minnows (Pimephales promelas) and allowed to swim freely in groups in 1000-L laboratory tanks equipped with temperatureregulation, biofiltration, water-recirculation, and aeration capacities. After 2 weeks, fish were placed individually in 70-L perforated plastic chambers submerged within the 1000-L experimental tanks and each fish was fed a half-maximum ration. Temperature and dissolved oxygen concentrations were monitored daily during acclimation and experimentation, while ammonia, nitrite, and nitrate concentrations were measured weekly. Temperatures remained within $0.5{ }^{\circ} \mathrm{C}$ of desired levels and dissolved oxygen concentrations remained above $7 \mathrm{mg} \cdot \mathrm{L}^{-1}$. Ammonia, nitrite, and nitrate concentrations did not exceed $0.003,0.25$, and $30.0 \mathrm{mg} \cdot \mathrm{L}^{-1}$, respectively.

During experiments, individual white crappie were weighed weekly (experiment 1) or every 10-20 days (experiments 2 6 ), including at the beginning and end of each experiment. Fish were starved for $24 \mathrm{~h}$ prior to weighing, held in a soft dip net to allow excess water to drain in a consistent manner, placed in a plastic container, and weighed to the nearest $0.1 \mathrm{~g}$. Fish total lengths (to the nearest $1.0 \mathrm{~mm}$ ) were measured whenever they were weighed.

Daily consumption was determined to the nearest $0.1 \mathrm{~g}$ for individual white crappie. Combined weights of blotted live fathead minnows were determined before providing them to each white crappie. Any uneaten minnows were removed from experimental chambers after $24 \mathrm{~h}$ and their combined weight was subtracted from that of minnows provided $24 \mathrm{~h}$ earlier. During submaximum feeding (experiments 1-3), weights of minnows provided daily were adjusted as the white crappie grew, to maintain constant consumption on a percent body weight basis.

Caloric densities of individual white crappie $\left(\mathrm{ED}_{\text {predator }}\right.$; $\mathrm{cal} \cdot \mathrm{g}$ wet $\mathrm{weight}^{-1} \cdot \mathrm{day}^{-1} ; 1 \mathrm{cal}=4.184 \mathrm{~J}$ ), which were required for bioenergetics modeling, were estimated throughout laboratory experiments from relative weights $\left(W_{\mathrm{r}}\right)(\mathrm{Ney}$ 1999) as

$$
\begin{array}{r}
\mathrm{ED}_{\text {predator }}=541.3+7.42 W_{\mathrm{r}} \\
\qquad\left(n=22, p<0.01, r^{2}=0.46\right)
\end{array}
$$

To construct this relationship, we selected white crappie experiencing conditions similar to experimental fish at the beginning, during, and upon completion of experiments. Wet and dry weights (to the nearest $0.1 \mathrm{~g}$ ), total length (to the nearest $1.0 \mathrm{~mm}$ ), and $W_{\mathrm{r}}$ were determined for each fish. Two 1-g samples from each fish were separately dried and pulverized, and the caloric density was determined by means of bomb calorimetry; the results were averaged to determine the mean caloric density. Fish caloric densities were re- gressed against corresponding wet and dry weights, total lengths, and $W_{\mathrm{r}}$ values. The relationship between caloric density and $W_{\mathrm{r}}$ alone was selected for estimating these values for experimental fish.

Energy densities of prey fish were also determined by bomb calorimetry. Five 50-g samples of fathead minnows (approximately 50 fish per sample) were taken throughout each experiment and bombed. Because the caloric densities of fathead minnows varied little within experiments, mean experiment-specific values $\left(964-1244 \mathrm{cal} \cdot \mathrm{g}\right.$ wet weight ${ }^{-1}$ ) were used in BEM simulations.

\section{Description of the BEM}

We modified an existing white crappie BEM (Zweifel 2000). Then, using data from the six laboratory experiments, we evaluated the modified model's ability to accurately predict observed white crappie consumption and growth. Ultimately, we corrected the modified model to reduce inherent systematic error and improve its predictive accuracy.

The modified white crappie BEM (Table 2) is based on the balanced energy equation used by Kitchell et al. (1977)

$$
G=C-(M+F+U)
$$

where growth $(G)$ over a time period is the difference between energy gained through food consumption $(C)$ and the sum of energy costs and losses through metabolism $(M)$, egestion $(F)$, and excretion $(U)$. All model variables are expressed in common units $\left(\mathrm{cal} \cdot \mathrm{g}^{-1} \cdot\right.$ day $\left.^{-1}\right)$.

Metabolic costs are represented by standard metabolism $\left(R_{\mathrm{s}}\right)$, hereinafter called resting routine metabolism (Jobling 1994), which is increased by activity cost (ACT) and by the costs of processing and assimilating consumed food, or specific dynamic action (SDA), as

$$
M=R_{\mathrm{S}} \mathrm{ACT}+\mathrm{SDA}
$$

as in Hanson et al. (1997). Resting routine metabolism is determined from the general body-weight- and temperaturedependent equation

$$
R_{\mathrm{s}}=\left(\beta_{0} W^{\beta_{1}}\right) \mathrm{e}^{\beta_{2} T}
$$

where $W$ is fish body weight ( $\mathrm{g}$ wet weight), $T$ is temperature $\left({ }^{\circ} \mathrm{C}\right), \beta_{0}$ and $\beta_{1}$ are intercept and slope values for the allometric function, respectively, and $\beta_{2}$ is the slope of temperature dependence of $R_{\mathrm{s}}$. Equation 4 differs from the equations used in the original white crappie BEM (Zweifel 2000) to determine $R_{\mathrm{s}}$. The original white crappie BEM determined $R_{\mathrm{S}}$ values from laboratory-derived resting routine metabolic rates of individually held white crappie ranging from 50 to $300 \mathrm{~g}$ at $18,21,24,27$, and $30^{\circ} \mathrm{C}$. Whereas $R_{\mathrm{S}}$ values are typically calculated from a single body-weight- and temperature-dependent equation (Kitchell et al. 1977; Hanson et al. 1997), Zweifel (2000) derived three such equations for distinct ranges of fish weight. However, subsequent evaluation revealed that unreasonable $R_{\mathrm{s}}$ values were produced by these three equations for certain conditions (fish body weight $>100 \mathrm{~g}$ under temperatures of $28-30{ }^{\circ} \mathrm{C}$ ). To ameliorate this problem, we fitted eq. 4 to the full range of white crappie metabolism data (Zweifel 2000) through multiple regression analysis. Although the resulting model explained only $35 \%$ of the variability in the data, overall it 
Table 2. Parameter values (and units) for the modified white crappie bioenergetics model (BEM) (uncorrected).

\begin{tabular}{llll}
\hline Parameter & Description & Value & Units \\
\hline Consumption & $(\boldsymbol{C})$ & & \\
$a$ & Intercept for body-weight dependence of $C_{\max }$ & 1389.9 & cal.g wet weight $^{-1}$ \\
$b$ & Slope for body-weight dependence of $C_{\max }$ & -0.661 & \\
$Q_{10}$ & Slope for temperature dependence of consumption & 2.945 & \\
$T_{\mathrm{m}}$ & Temperature above which consumption ceases & 32 & ${ }^{\circ} \mathrm{C}$ \\
$T_{\mathrm{o}}$ & Temperature at which consumption is maximal & 24 & ${ }^{\circ} \mathrm{C}$
\end{tabular}

Respiration $(M)$

Resting routine metabolism $\left(R_{\mathrm{s}}\right)$

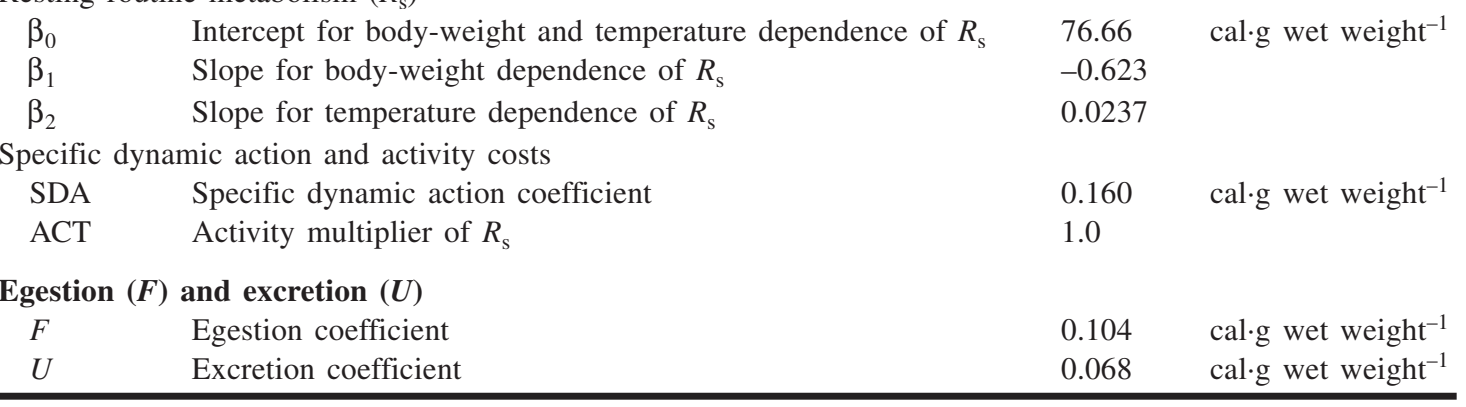

Note: The modified model is identical with the original model of Zweifel (2000) except that resting routine metabolism $\left(R_{\mathrm{s}}\right)$ is determined from a multiple regression equation. Associated equations (or citations for them) are given in the text. $1 \mathrm{cal}=4.184 \mathrm{~J}$.

provided more reasonable $R_{\mathrm{s}}$ values $(0.4 \%-2 \%$ body weight. day $^{-1}$ ) than were given by the set of three equations.

The activity multiplier (ACT) in eq. 3 accounts for metabolic costs in excess of resting routine metabolism relating to, for example, swimming, prey pursuit, and activity and stress from social interaction. For fish in our laboratory experiments, activity costs were assumed to be negligible $(\mathrm{ACT}=1)$ because fish were held in relatively small, $70-\mathrm{L}$ chambers that allowed very limited opportunity for swimming. When fed, fish were observed to slowly approach and readily capture their prey with little rapid movement. During nonfeeding periods, only minor spontaneous movement was observed. Moreover, holding fish individually eliminated activity due to social interaction.

Relationships among consumption $(C)$, maximum daily consumption $\left(C_{\max }\right)$, proportion of maximum consumption ingested $(P)$, and the influences of body weight and temperature on $C_{\max }$ and $C$ are as defined in consumption equation 2 of Hanson et al. (1997).

$F, U$, and SDA values in both the original and modified model were determined as

$$
\begin{aligned}
& F=0.104 C \\
& U=0.068(C-F)
\end{aligned}
$$

and

$$
\mathrm{SDA}=0.160(C-F)
$$

The general forms of eqs. 5-7 are commonly used in fish BEMs (Hanson et al. 1997).

\section{Predicting growth and consumption}

The modified white crappie BEM was run to predict abso-

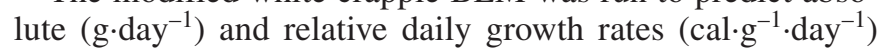
of individual white crappie throughout each of the six laboratory experiments. On the first day of a model run, pre- dicted body weight was set at a fish's observed initial body weight. For each daily time step, an observed daily consumption value $(\mathrm{g})$ was entered and converted to caloric intake according to prey caloric density. The model then calculated a daily value for resting routine metabolism $\left(R_{\mathrm{s}}\right.$; cal.g wet weight ${ }^{-1}$ ) from predicted body weight and observed temperature. Consumption losses through $F$ and $U$ and metabolic cost of SDA (all in cal.g wet weight ${ }^{-1}$ ) were calculated as fractions of either daily caloric consumption $(C)$ or digested energy $(C-F)$. Total energy costs and losses were then subtracted from daily consumption, yielding daily growth in cal.g wet weight ${ }^{-1}$, which was converted to body mass using a daily caloric density value for white crappie. Caloric densities of individual white crappie were estimated from the mean of observed $W_{\mathrm{r}}$ values over 20-day experiment subperiods (eq. 1). Daily growth was accumulated over time to produce a predicted growth trajectory.

The modified BEM was also run to estimate daily consumption rates $\left(\mathrm{cal}^{-\mathrm{g}^{-1}} \cdot \mathrm{day}^{-1}\right.$, and also $\%$ body weight $\cdot \mathrm{day}^{-1}$ ) and, ultimately, cumulative consumption ( $g$ prey) for each fish in each of the six laboratory experiments. Consumption estimates were made using the $P$-fit approach (Kitchell et al. 1977; Hewett and Johnson 1992). Through an iterative process this determines the fixed proportion $(P)$ of maximum daily consumption $\left(C_{\max }\right)$ that causes the model to grow a fish from its observed initial weight to its observed final weight over the total number of days in a modeling interval under the observed thermal conditions. Fitted $P$ values were converted to daily consumption rates using predicted daily weights of individual fish and observed temperatures. Estimated daily consumption rates $\left(\mathrm{cal} \cdot \mathrm{g}^{-1}\right)$ were then converted to grams of food consumed using prey caloric density and white crappie weight and summed over days in the modeling interval to estimate cumulative consumption ( $g$ prey).

When estimating consumption for individual fish using the modified BEM, laboratory experiments were first di- 
vided into three subperiods of 15-25 days each during which combinations of ration level, temperature, and white crappie body weight remained similar (Table 1). This measure was taken so that measured levels of predictive error for the BEM could be linked to specific levels of consumption, temperature, and fish weight. Such subperiods were formed even for experiments 2 and 3, throughout which applied temperatures and ration levels remained constant. A single $P$-fit procedure was conducted for each fish within each subperiod of each experiment. Predicted cumulative consumption values for individual fish over whole experiments were calculated by summing predicted cumulative consumption over the component subperiods.

\section{Representing the accuracy of model predictions}

The accuracy of white crappie growth and consumption predictions by the modified BEM was described for each of the six laboratory experiments that collectively represented growth conditions ranging from highly favorable to poor (Table 1). Growth-prediction accuracy was determined by comparing predicted with observed growth trajectories for each fish in each experiment. The accuracy of growth predictions was represented as (i) the mean of absolute daily growth errors (MGE) and also as (ii) the maximum of absolute daily growth errors (MaxGE), each expressed as a percentage of observed mean body weight (or single-day body weight for MaxGE) (Bajer et al. 2003). MGE represents the average departure of a predicted growth trajectory from the corresponding observed trajectory

$$
\mathrm{MGE}=\frac{\sum_{i=1}^{n}\left|\frac{\left(P_{i}-O_{i}\right)}{O_{i}}\right|}{n} \times 100
$$

where $P_{i}$ and $O_{i}$ are predicted and observed body weights on day $i$ of a growth trajectory, respectively, and $n$ is the total number of days in the trajectory. Absolute values of relative daily differences between predicted and observed values were used because modeled trajectories can cross over observed trajectories; if absolute values are not used, negative errors will be subtracted from positive errors, causing underrepresentation of overall mean error. Maximum daily errors were determined as

$$
\operatorname{MaxGE}=\max \left|\frac{\left(P_{i}-O_{i}\right)}{O_{i}}\right| \times 100
$$

MaxGE values indicate volatility of model predictions that may not be evident from MGE. For example, a high MaxGE value relative to the MGE value for a pair of predicted and observed growth trajectories would highlight a situation where predicted and observed values agree well over much of a modeling interval, but predicted values depart substantially from observed values near the interval's end.

The accuracy of consumption predictions by the modified white crappie BEM was likewise determined from individual fish responses and considered differences between predicted and observed cumulative consumption over whole experiments. The accuracy of model predictions of cumulative consumption for each fish was expressed as cumulative consumption error (CCE), calculated as the difference between predicted and observed cumulative consumption values on the final day of a modeled trajectory, expressed as a percentage of observed final-day cumulative consumption

$$
\mathrm{CCE}=\left(P_{\mathrm{f}}-O_{\mathrm{f}}\right) / O_{\mathrm{f}} \times 100
$$

where $P_{\mathrm{f}}$ and $O_{\mathrm{f}}$ are predicted and observed cumulative consumption values on the final day of a modeled trajectory, respectively.

\section{Identifying systematic error and its sources}

Three primary input/output variables for BEMs (hereinafter PIO variables), fish body weight $(\mathrm{g})$, daily consumption $\left(\mathrm{cal}^{\mathrm{g}} \mathrm{g}^{-1} \cdot \mathrm{day}^{-1}\right)$, and temperature $\left({ }^{\circ} \mathrm{C}\right)$, were used to explore possible systematic error in the modified white crappie model. It was reasonable to use the PIO variables to search for systematic error because each influences values of one or more of the internal energy cost/loss variables $\left(R_{\mathrm{s}}, \mathrm{SDA}, F\right.$, and $\left.U\right)$ within the BEM with the exception of activity (ACT). Inadequacies in the internal relationships between the energy cost/loss variables and their associated PIO variables (e.g., eqs. 5-7) would promote systematic error in the BEM. Ideally, the BEM prediction error rate will remain close to zero across all levels of fish body weight, daily consumption, or temperature. The presence of correlation between model prediction error rates and levels of any of the PIO variables would indicate inadequacies in the BEM's internal equations and the presence of systematic error. Regression analysis can provide a quantitative description of any such relationships between PIO variables and model prediction error rates that result from systematic error. Such correlation will also indicate likely sources of systematic model error because each PIO variable has known linkages to particular energy cost/loss variables within the model.

To explore possible systematic error in the modified white crappie BEM, we looked for correlation between the three PIO variables and the magnitude of model prediction error. A growth rate prediction error (GRE) value and a consumption rate prediction error (CRE) value were determined for each fish within each of the three subperiods of each laboratory experiment. Individual GRE and CRE values were determined within experiment subperiods (Table 1) instead of over whole experiments so that each model prediction error value would be associated with relatively static levels of daily consumption, temperature, and fish body weight (the PIO variables). A total of 117 GRE values (three subperiods times the total number of fish per experiment, summed over the six experiments) were produced, and likewise for CRE values, each being associated with a mean daily consumption, temperature, and body-weight value for an individual fish from a subperiod.

For each of the 18 experiment subperiods, a GRE value

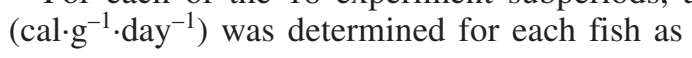

$$
\mathrm{GRE}=\frac{\left(P_{\mathrm{f}}-O_{\mathrm{f}}\right)}{n \bar{O}} \cdot \mathrm{ED}_{\text {predator }}
$$

where $P_{\mathrm{f}}$ and $O_{\mathrm{f}}$ are predicted and observed fish weights at the end of a subperiod, respectively, $\bar{O}$ is mean observed fish weight during the subperiod, $n$ is the number of days in the subperiod, and $\mathrm{ED}_{\text {predator }}$ is predator energy density $\left(\mathrm{cal} \cdot \mathrm{g}^{-1}\right)$ 
during the subperiod. A CRE value $\left(\mathrm{cal}^{\mathrm{g}} \mathrm{g}^{-1} \cdot \mathrm{day}^{-1}\right)$ was also determined for each fish in each experiment subperiods as

$$
\mathrm{CRE}=\frac{\left(P_{\mathrm{f}}-O_{\mathrm{f}}\right)}{n \bar{O}} \cdot \mathrm{ED}_{\text {prey }}
$$

where $P_{\mathrm{f}}$ and $O_{\mathrm{f}}$ are predicted and observed cumulative consumption values on the final day of a subperiod, respectively, $n$ and $\bar{O}$ are as previously defined, and $\mathrm{ED}_{\text {prey }}$ is prey energy density.

Before conducting simple regressions of GRE and CRE values on corresponding values of each of the three PIO variables, potential non-independence within the regression data sets was eliminated. The potential for non-independence existed because an individual fish's responses were measured 3 times, once in each of the three subperiods within an experiment. To eliminate this, we randomly selected and retained only one of the three sets of error data per fish. This reduced the total number of observations in each simple regression analysis by two-thirds, resulting in 39 observations for each. We evaluated similarity among regressions of GRE and CRE values on each of the three PIO variables (six simple regressions) that arose from 10 distinct random selections of one of the three possible sets of data per fish. The slopes and intercepts of the 10 randomly selected versions of each of the six regressions did not differ (heterogeneity of slopes analysis followed by analysis of covariance, $p>0.05$ ), indicating good stability among the relationships between PIO variables and both GRE and CRE values.

\section{Correcting the BEM for systematic error}

Following examination of simple regression results, all three PIO variables (daily consumption, body weight, and temperature) were included in various linear combinations as predictor variables in multiple regression analyses aimed at developing a best GRE prediction equation for the modified white crappie BEM. A separate equation was similarly constructed for predicting CRE values. These two equations would ultimately be incorporated into the BEM to correct prediction error on a daily time-step basis. The effectiveness of incorporating these correction equations to improve BEM predictions was subsequently evaluated via a cross-validation procedure. Parameter-selection criteria for the best multiple regression models included Akaike's information criterion (AIC) scores and, to a lesser degree, improvement in $R^{2}$ values. In general, we selected models with the fewest parameters whose AIC scores were within seven points of the lowest AIC values observed (Burnham and Anderson 2001). Selected multiple regression models were evaluated for goodness of fit to the GRE and CRE data and for the need to include interaction terms based on examination of residual plots.

When constructing the correction equation for CRE values, we used the observed white crappie growth rate (GRATE; $\mathrm{cal} \cdot \mathrm{g}^{-1} \cdot \mathrm{day}^{-1}$ ) as a surrogate predictor variable for daily consumption. For BEM applications aimed at estimating food consumption, observed daily consumption data will clearly not be available for CRE correction, unlike in our laboratory experiments designed specifically for model evaluation. GRATE is an appropriate surrogate variable for daily consumption when predicting CRE values, because it tends to be well correlated with daily consumption level both in laboratory and natural settings (Davis and Warren 1971; Carline and Hall 1973; Allen and Wootton 1982).

\section{Evaluation of the corrected BEM}

Cross-validation (Neter et al. 1996) was used to independently evaluate whether white crappie BEM predictions were improved by including error-correction equations. For this evaluation, error-correction equations for both consumption and growth predictions developed from the full data set were redeveloped using halves of the data set. The two half data sets each included information from three laboratory experiments that were randomly selected without replacement, with one of the two weight-loss experiments (experiments 2 and 3) being forced at random into each half data set. As was done for the full data set, multiple regression analyses were used to develop BEM correction equations for consumption and growth predictions for each half data set. (Hereinafter, correction equations developed from halves of the data set are correction "subequations", while those based on all six experiments are "full" correction equations.) Correction subequations were forced to include the same predictor variables (PIO variables) that had been selected for the full correction equations. First, GRE, CRE, and associated PIO values were generated by using the uncorrected BEM (the modified BEM without correction equations) to predict growth and consumption rates for one half of the data (experiments 1, 3, and 5). Two correction subequations (one predicting GRE values and the other, CRE values) were then developed from this half data set and incorporated into the BEM. This corrected model was then used to predict growth and consumption for fish in the other half data set (experiments 2, 4, and 6). This procedure was then run in the opposite direction so that data from experiments 2,4 , and 6 were used to develop correction subequations, and the corrected BEM containing these equations was tested on experiments 1,3 , and 5. Results from the two procedures were then combined. Whereas full correction equations were derived from 39 sets of GRE and CRE values and associated PIO values, correction subequations were derived from 20 (experiments 1,3 , and 5) and 19 (experiments 2, 4, and 6) sets. When running corrected models, growth and consumption predictions were modified in each daily time step in accordance with the amount of predictive error estimated by the correction subequations in response to daily values of the PIO variables.

Improvement of the white crappie BEM's predictive accuracy from inclusion of correction subequations was assessed by comparing uncorrected model predictions with those from the independently corrected models. Absolute (body weight (g) and cumulative consumption $(\mathrm{g})$ ) as well as relative model predictions (growth rates $\left(\mathrm{cal} \cdot \mathrm{g}^{-1} \cdot \mathrm{day}^{-1}\right)$ and consumption rates $\left.\left(\mathrm{cal} \cdot \mathrm{g}^{-1} \cdot \mathrm{day}^{-1}\right)\right)$ were evaluated. To visually assess improvements, plots of predicted mean growth trajectories from uncorrected and corrected models were compared with observed mean growth trajectories for each of the six laboratory experiments. For each experiment, differences between mean values of MGE, MaxGE, and CCE for the corrected versus uncorrected models were evaluated by means of paired $t$ tests ( $p<0.025$, one-tailed tests), with pairing based on modeling error for an individual fish's trajectories of growth and consumption. Heterogeneity of slopes tests 
Fig. 1. Observed mean growth trajectories \pm 1 standard error (SE) for white crappie (Pomoxis annularis) in laboratory experiments 1-6 ( $a-f$, respectively) compared with means of predicted growth trajectories by the uncorrected (solid line) and corrected (broken line) white crappie bioenergetics models (BEMs). Fish continually lost weight, owing to the imposition of submaintenance rations in experiments 2 and 3, but gained weight under moderate to high ration levels in all other experiments. Note that $y$-axis scales vary among the six panels.
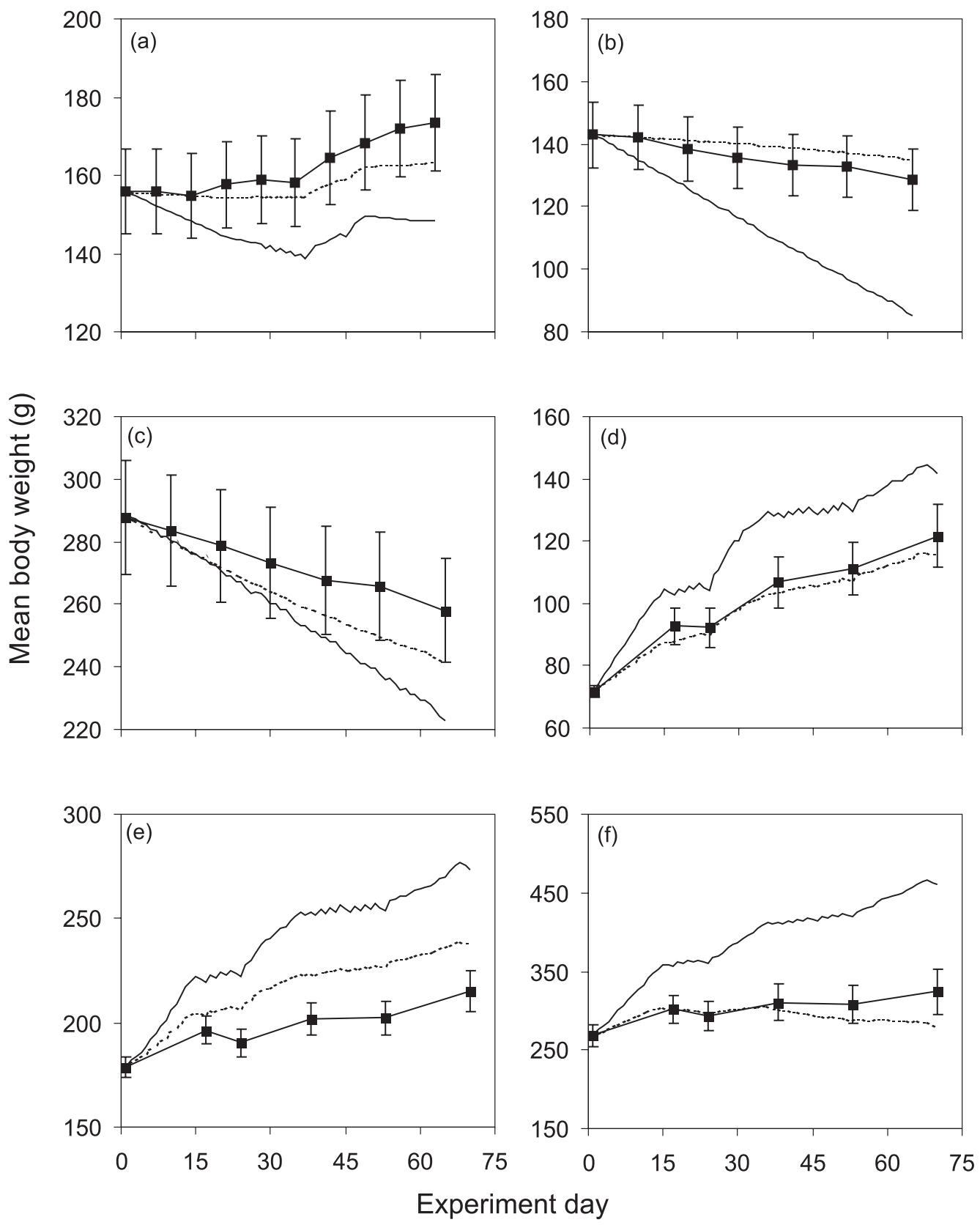

$(p<0.025$, one-tailed tests) were also applied to determine whether the inclusion of independently derived correction subequations diminished the slopes of originally observed relationships between GRE and CRE values and the PIO variables, which portrayed systematic model error. Changes in intercept values for the same relationships were considered significant if the pre- and post-correction intercepts \pm 2 standard errors (SEs) did not overlap. Observed improvements in BEM predictive accuracy based on cross-validation are considered indicative of improvement that will result when the white crappie model with full correction equations is applied over conditions encompassed by the six laboratory experiments.

\section{Results}

Accuracy of the BEM before correction

Overall, predicted growth trajectories by the uncorrected white crappie BEM were reasonably accurate (Fig. 1), but the accuracy varied considerably across the six experiments. MGE ranged from about 7\% (experiment 3: 275-g fish fed at $0.5 \%$ body weight daily at $27{ }^{\circ} \mathrm{C}$ ) to $28 \%$ (experiment 6 : 
Table 3. Mean (MGE) and maximum (MaxGE) errors for predictions of fish growth in the six laboratory experiments by the uncorrected and corrected white crappie BEMs.

\begin{tabular}{|c|c|c|c|c|c|}
\hline \multirow[b]{2}{*}{ Exp. No. } & \multirow[b]{2}{*}{ Growth condition } & \multicolumn{2}{|l|}{ MGE } & \multicolumn{2}{|l|}{ MaxGE } \\
\hline & & Uncorrected & Corrected & Uncorrected & Corrected \\
\hline 1 & Moderate gain & $10.0(1.8)$ & $3.3 *(0.8)$ & $16.5(2.7)$ & $6.7 *(1.1)$ \\
\hline 2 & Loss & $17.1(1.5)$ & $3.2 *(0.8)$ & $35.2(2.6)$ & $5.7 *(1.2)$ \\
\hline 3 & Loss & $6.5(0.7)$ & $3.7(0.8)$ & $14.9(1.6)$ & $7.5^{*}(1.8)$ \\
\hline 4 & Rapid gain & $15.7(3.7)$ & $2.7 *(0.3)$ & $24.0(3.9)$ & $6.5 *(1.3)$ \\
\hline 5 & Rapid gain & $20.1(3.2)$ & $9.1 *(1.4)$ & $29.5(4.5)$ & $14.3 *(1.9)$ \\
\hline 6 & Rapid gain & $27.7(3.9)$ & $6.6^{*}(1.3)$ & $42.5(6.9)$ & $14.5 *(4.4)$ \\
\hline
\end{tabular}

Note: Applied conditions produced weight loss or moderate or rapid weight gain. MGE and MaxGE values (both as \% body weight:day ${ }^{-1}$ ) represent mean and maximum daily departures of model-predicted from observed growth trajectories, respectively. Differences between MGE values for the corrected versus uncorrected model were evaluated using paired $t$ tests for each experiment (an asterisk indicates significantly lower error (one-tailed test) for the uncorrected model at $p \leq 0.05$ and likewise for MaxGE; $p=0.06$ for the decline in MGE for experiment 3). Values in parentheses are standard errors.

Table 4. Mean values of observed cumulative consumption by white crappie in each laboratory experiment, predicted cumulative consumption by the uncorrected and corrected BEMs and consumption prediction errors (CCE) for each model.

\begin{tabular}{|c|c|c|c|c|c|}
\hline \multirow[b]{3}{*}{ Exp. No. } & \multicolumn{3}{|c|}{ Cumulative consumption $(\mathrm{g})$} & \multirow{2}{*}{\multicolumn{2}{|c|}{$\operatorname{CCE}(\%)$}} \\
\hline & & Model-predic & & & \\
\hline & Observed & Uncorrected & Corrected & Uncorrected model & Corrected model \\
\hline 1 & $117(10)$ & $160(7)$ & $141(9)$ & $42.3(9.1)$ & $25.7 *(9.3)$ \\
\hline 2 & $39(3)$ & $124(4)$ & $25(6)$ & $224.0(17.9)$ & $-36.1 *(12.7)$ \\
\hline 3 & $78(4)$ & $142(3)$ & $117(17)$ & $84.5(9.5)$ & $46.1(15.4)$ \\
\hline 4 & $188(24)$ & $152(16)$ & $174(27)$ & $-17.6(2.9)$ & $-8.95(3.29)$ \\
\hline 5 & $246(31)$ & 169 (19) & $216(42)$ & $-30.4(2.9)$ & $-14.9(7.0)$ \\
\hline 6 & $400(70)$ & $223(32)$ & $376(84)$ & $-42.6(2.6)$ & $-10.31 *(7.7)$ \\
\hline
\end{tabular}

Note: Differences in mean CCE values for the uncorrected and corrected models were evaluated by using paired $t$ tests for each experiment (an asterisk indicates significantly lower error (one-tailed test) for the uncorrected model at $p \leq 0.05 ; p=$ $0.075,0.060$, and 0.053 for experiments 3,4 , and 5 , respectively). Values in parentheses are standard errors.

300-g fish fed ad libitum at $\left.24-30{ }^{\circ} \mathrm{C}\right)$, while MaxGE ranged from $15 \%$ (experiment 3 ) to $43 \%$ (experiment 6) (Table 3 ). Predicted mean body weight trajectories exceeded 1 SE of observed trajectories for all six experiments, and exceeded 2 SEs for four experiments (Fig. 1).

Prediction error for cumulative consumption by the uncorrected model was more variable across experiments than for growth predictions. Lower CCE values (17\%-43\%) were observed for fish gaining weight (experiments 1 and 4-6), while substantially higher CCE values (84\%-224\%) were observed for fish undergoing weight loss due to submaintenance feeding (experiments 2 and 3) (Table 4).

\section{Evaluating sources of systematic error in the model}

Simple linear regression analyses showed that the uncorrected model's predictive error for both growth and consumption rates during subperiods of the six laboratory experiments was strongly correlated with observed mean daily

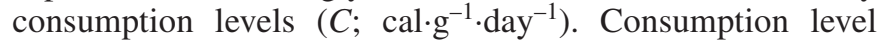
was positively correlated with GRE and negatively correlated with CRE. Daily consumption level accounted for $81 \%$ and $82 \%$ of the total variation associated with GRE and CRE, respectively (Table 5). The uncorrected model increasingly overestimated growth rate (Fig. 2a) and underestimated consumption rate (Fig. 2c) as daily consumption levels increased above $20 \mathrm{cal} \cdot \mathrm{g}^{-1} \cdot \mathrm{day}^{-1}$ (approximately $1.5 \%$ body weight $\cdot$ day $^{-1}$ ), while the opposite was true for consumption levels below $20 \mathrm{cal} \cdot \mathrm{g}^{-1} \cdot \mathrm{day}^{-1}$.

Temperature was negatively correlated with GRE and positively correlated with CRE for the uncorrected model (Table 5), but these correlations were substantially weaker than those between predictive error and consumption level. The PIO variables temperature and consumption level were intercorrelated $\left(r^{2}=0.44, p=0.004\right)$, and this may have accounted for some of temperature's association with GRE and CRE.

Overall, fish body weight was not correlated with GRE or CRE (Table 5). However, closer investigation revealed that body weight was strongly correlated with GRE (positively) and CRE (negatively) for fish that were losing weight (experiments 2 and 3) but not for fish gaining weight (Figs. $3 a$ and $3 b$ ). For fish losing weight, body weight explained $94 \%$ $\left(F_{[1,12]}=204.5, p<0.0001\right)$ of the variation in GRE and $96 \%\left(F_{[1,12]}=246.1, p<0.0001\right)$ of that in CRE. For white crappie $<350 \mathrm{~g}$ that were losing weight, the uncorrected BEM increasingly underestimated relative growth rate and overestimated relative consumption rate as fish size decreased. Body weight was not correlated with consumption $\left(F_{[1,37]}=1.1, p=0.29\right)$ or temperature $\left(F_{[1,37]}=0.3, p=\right.$ $0.58)$.

As expected, the observed GRATE value $\left(\right.$ cal $\cdot \mathrm{g}^{-1} \cdot \mathrm{day}^{-1}$ ) for white crappie was strongly correlated with observed daily 
Table 5. Simple linear regressions of BEM-predicted growth-rate errors (GRE values) and consumption-rate errors $\left(\mathrm{CRE}\right.$ values) (both in $\mathrm{cal} \cdot \mathrm{g}^{-1} \cdot \mathrm{day}^{-1} ; 1 \mathrm{cal}=4.184 \mathrm{~J}$ ) versus mean daily consumption $\left(C ; \mathrm{cal}^{-1} \cdot \mathrm{g}^{-1} \cdot \mathrm{day}^{-1}\right)$, fish body weight $(W ; \mathrm{g})$, and temperature $\left(T ;{ }^{\circ} \mathrm{C}\right)$ across all six laboratory experiments.

\begin{tabular}{|c|c|c|c|c|c|c|}
\hline Response variable & Predictor variable & $\beta_{0}$ & $\beta_{1}$ & $F_{[1,37]}$ & $r^{2}$ & $p$ \\
\hline \multicolumn{7}{|l|}{ Uncorrected BEM } \\
\hline GRE & $C$ & -5.99 & 0.32 & 180.7 & 0.81 & 0.0001 \\
\hline GRE & $T$ & 43.8 & -1.61 & 8.64 & 0.18 & 0.005 \\
\hline GRE & $W$ & -2.24 & 0.019 & 1.72 & 0.05 & 0.19 \\
\hline CRE & $C$ & 9.53 & -0.51 & 193.3 & 0.82 & 0.0001 \\
\hline CRE & $T$ & -80.5 & 2.96 & 11.97 & 0.24 & 0.001 \\
\hline CRE & $W$ & 2.93 & -0.028 & 1.46 & 0.04 & 0.23 \\
\hline CRE & GRATE & 3.87 & -1.52 & 94.8 & 0.72 & 0.0001 \\
\hline \multicolumn{7}{|l|}{ Corrected BEM } \\
\hline GRE & $C$ & $0.045^{*}$ & $-0.034 *$ & 4.68 & 0.11 & 0.04 \\
\hline GRE & $T$ & 3.65 & -0.16 & 1.28 & 0.03 & 0.46 \\
\hline GRE & $W$ & -0.23 & -0.0028 & 0.49 & 0.01 & 0.47 \\
\hline CRE & $C$ & $1.61 *$ & $-0.10 *$ & 9.1 & 0.19 & 0.004 \\
\hline CRE & $T$ & -22.9 & 0.84 & 5.11 & 0.11 & 0.03 \\
\hline CRE & $W$ & -3.80 & 0.016 & 2.7 & 0.07 & 0.11 \\
\hline CRE & GRATE & 0.16 & $-0.21^{*}$ & 3.58 & 0.08 & 0.07 \\
\hline
\end{tabular}

Note: Separate regressions are shown for the uncorrected and corrected BEMs. Regression results for the predictor variable growth rate (GRATE; cal $\cdot \mathrm{g}^{-1} \cdot \mathrm{day}^{-1}$ ) were applicable to CRE values only. An asterisk indicates significantly reduced values of $\beta_{0}$ (intercept) and $\beta_{1}$ (slope). Decreases in slope were determined by means of heterogeneity of slopes tests at $p \leq 0.05$ (one-tailed test). The intercept was considered to be lower for the corrected BEM if the intercept mean \pm 2 SEs was lower than and did not overlap that of the uncorrected model.

consumption $\left(F_{[1,37]}=833, r^{2}=0.97, p<0.0001 ;\right.$ Fig. $\left.4 a\right)$ over the range of growth conditions provided in experiments 1-6. Ultimately, GRATE was used as the necessary surrogate variable for observed daily consumption in the process of building a multiple regression equation for predicting CRE values and correcting consumption predictions by the BEM. GRATE was negatively correlated with CRE and explained $72 \%$ of its total variation (Table 5; Fig. 4b). Although daily consumption was a better predictor of CRE, its applicability beyond laboratory evaluations is limited. In most cases it should be possible to use GRATE in place of consumption level when forming correction equations.

\section{Development of error-correction equations}

A multiple regression model containing three predictor variables, body weight $(W)$, body weight interacting with temperature $(W \cdot T)$, and consumption interacting with temperature $(C \cdot T)$, was selected as the best model for predicting GRE values in the white crappie BEM based on AIC and adjusted $R^{2}$ values $\left(F_{[2,35]}=357.9, R^{2}=0.96, p<0.0001\right.$; Table 6). The resulting equation for correcting growth predictions by the BEM was

$$
\begin{aligned}
& \mathrm{GRE}=-13.54+0.108 W-0.0026(W T) \\
&+0.013(C T)
\end{aligned}
$$

A two-predictor-variable model containing relative growth rate (GRATE, the surrogate variable for consumption) and body weight was selected for predicting CRE values $\left(F_{[2,36]}=122.3, R^{2}=0.86, p<0.0001\right.$; Table 6). The resulting equation for correcting consumption predictions was

$$
\mathrm{CRE}=15.81-1.67 \mathrm{GRATE}-0.061 \mathrm{~W}
$$

Equations 13 and 14 could ultimately be incorporated into the uncorrected white crappie BEM to form a corrected model if cross-validation assessments indicated that their inclusion would lead to significantly more accurate predictions of growth and consumption.

\section{Evaluation of the corrected BEM}

Growth and consumption predictions were generated by the two corrected versions of the white crappie BEM. Each version included correction subequations with the same predictor variables as in eqs. 13 and 14 , but with distinct coefficient values that were derived by applying multiple regression analysis to the data from experiments 1, 3, and 5, and separately to the data from experiments 2,4 , and 6 . A corrected model incorporating correction subequations from the data from experiments 1,3 , and 5 was used to predict observed growth and consumption of individual fish in experiments 2,4 , and 6 , and vice versa.

Predicted mean growth trajectories resulting from inclusion of correction subequations in the cross-validation procedure consistently tracked much closer to observed trajectories than those predicted by the uncorrected model (Fig. 1). Across all six experiments, MGE and MaxGE values for corrected models were 2-4 times lower than corresponding values for the uncorrected model. MGE and MaxGE values remained below $10 \%$ and $15 \%$, respectively, versus $28 \%$ and $43 \%$ for the uncorrected model (Table 3). Observed decreases in MGE and MaxGE were statistically significant or marginally so (paired $t$ tests, $p<0.025,0.05$, one-tailed tests) except for MGE in experiment 3 , the only experiment in which prediction error for the uncorrected model was $<10 \%$.

Predictions of cumulative consumption likewise improved from incorporation of correction subequations into the white crappie BEM (Table 4). For fish gaining weight (experiments 1 and 4-6), CCE remained below 26\%, whereas the highest CCE value approached $43 \%$ for the uncorrected model. For fish losing weight (experiments 2 and 3), origi- 
Fig. 2. (a) Regression relationships of uncorrected BEM growth prediction error (GRE) for individual fish versus the observed mean daily consumption rate of fish over corresponding modeling intervals. (b) Similarly for the GRE of the corrected BEM (derived by cross-validation; $\bigcirc$ and $\bigcirc$ represent independent predictions by each of the corrected half-models). (c) Uncorrected BEM prediction error for consumption rate (CRE) versus each fish's observed mean daily consumption rate over corresponding modeling intervals. (d) Similarly for the CRE from the corrected BEM. All four regression relationships were significant $(p<0.05)$. Slopes and intercepts for regressions related to corrected models $(b$ and $d$ ) were significantly closer to zero than for corresponding regression relationships for the uncorrected model ( $a$ and $c$ ) (slope differences were evaluated by means of heterogeneity of slopes tests at $p \leq 0.025$, onetailed test; intercepts were considered to differ if the intercept means \pm 2 SEs did not overlap). 1 cal $=4.184 \mathrm{~J}$.
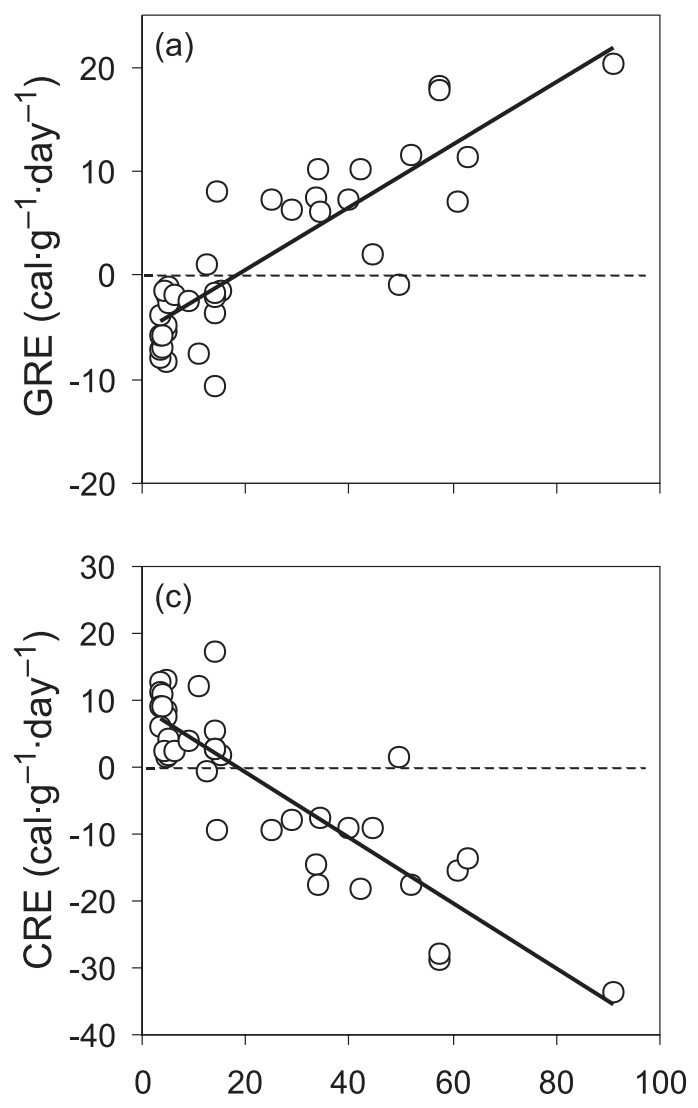
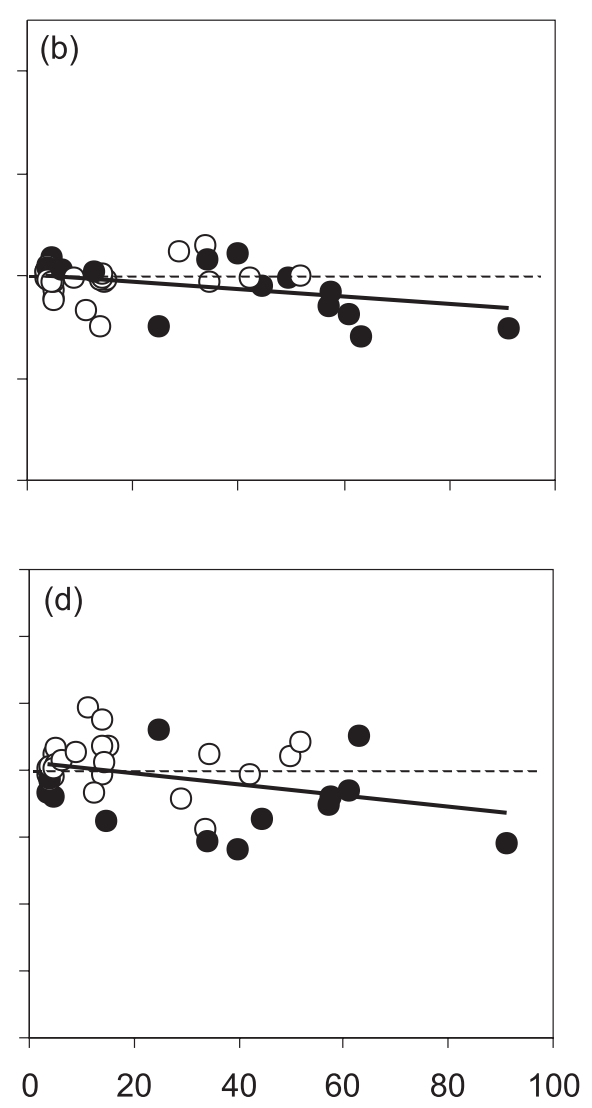

\section{Mean daily consumption $\left(\mathrm{cal}^{\mathrm{g}} \mathrm{g}^{-1} \cdot \mathrm{day}^{-1}\right)$}

nally high errors of $224 \%$ and $84 \%$ decreased to $36 \%$ and $46 \%$, respectively. Observed declines in CCE values were significant (or marginally so) for three of the six experiments (paired $t$ test, $p \leq 0.025,0.05$, one-tailed tests; Table 4). For experiments 3, 4, and 5, where declines in CCE were nonsignificant, mean CCE values declined $45 \%, 49 \%$, and $51 \%$, respectively, when correction equations were included.

\section{Systematic error after model correction}

Errors associated with predictions of growth rates (GRE values) and consumption rates (CRE values) were reevaluated for the corrected model through the cross-validation procedure. The previously observed strong influence of mean daily consumption on GRE in the uncorrected BEM (Fig. 2a) was markedly reduced (Fig. 2b). A significant relationship between daily consumption and GRE remained after correction (Table 5), but the previous high positive regression slope decreased to a slight negative value and the intercept was significantly reduced to near zero. A slight tendency to underestimate growth rate as consumption level increased was indicated for the corrected model over the entire range of consumption levels evaluated $\left(0-90 \mathrm{cal} \cdot \mathrm{g}^{-1} \cdot \mathrm{day}^{-1}\right.$, equivalent to $0 \%-8 \%$ body weight $\cdot \mathrm{day}^{-1}$; Fig. $\left.2 b\right)$. The previously significant negative relationship between GRE and temperature became nonsignificant after correction (Table 5), indicating a lack of systematic error associated with temperature in the corrected model. Overall, fish body weight was not correlated with GRE either before or after model correction. However, the highly significant influence of body weight on GRE exclusively for fish losing weight was much reduced after model correction (Fig. 5a). Although a significant relationship between GRE and fish body weight remained after correction, the indicated biasing effect was minor.

An improved capacity to predict consumption rates after model correction was likewise indicated by the cross-validation procedure. The previous strong effect of daily consumption level on CRE (Fig. 2c) was much reduced (Fig. 2d). Although the relationship between CRE and daily consumption remained significant after correction, as for GRE, regression slope and intercept values were altered significantly to val- 
Fig. 3. (a) Regression relationships for growth rate prediction er-

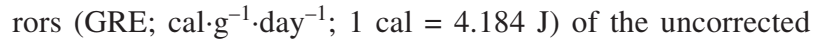
BEM versus mean body weights of individual white crappie over modeling intervals; the regression analysis based on all observations $(\bigcirc$ plus $\bigcirc)$ was nonsignificant $(p>0.05)$; however, the regression based exclusively on fish that were losing weight $(0)$ was highly significant $\left(\mathrm{GRE}=-10.48+0.030 \mathrm{~W} ; F_{[1,12]}=204.5\right.$, $\left.r^{2}=0.95, p<0.0001\right)$. (b) Similarly for the consumption rate prediction errors of the uncorrected model $\left(\mathrm{CRE}\right.$; cal $\left.\cdot \mathrm{g}^{-1} \cdot \mathrm{day}^{-1}\right)$; again, the regression analysis based on all observations ( $\bigcirc$ plus O) was nonsignificant $(p>0.05)$, while that based exclusively on fish that were losing weight was highly significant $(\mathrm{CRE}=$ $\left.16.64-0.0483 W ; F_{[1,12]}=246.1, r^{2}=0.93, p<0.0001\right)$.
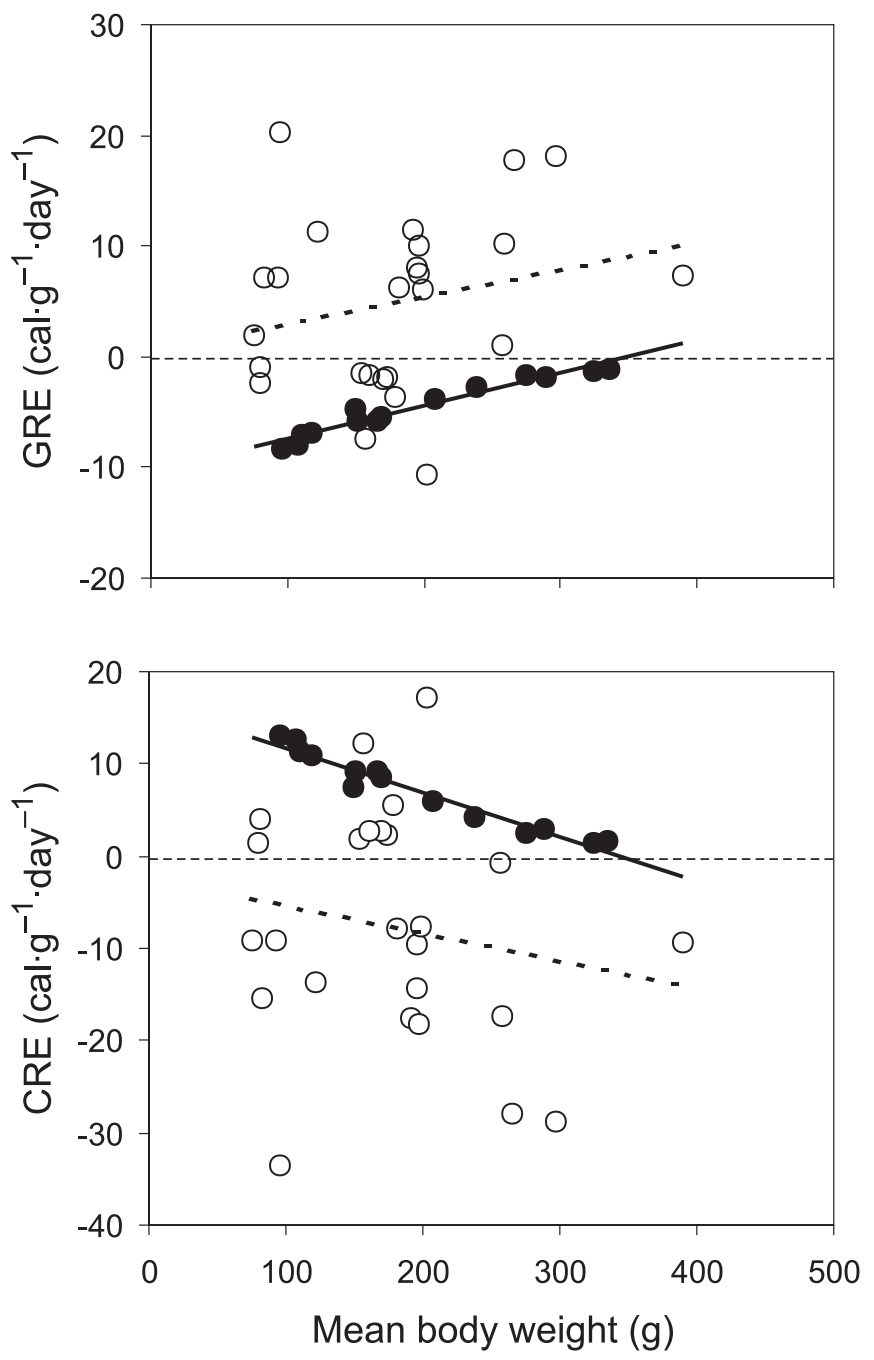

ues close to zero (Table 5). A slight tendency to overestimate consumption at very low ration levels $\left(<10 \mathrm{cal} \cdot \mathrm{g}^{-1} \cdot \mathrm{day}^{-1}\right.$, equivalent to $<1 \%$ body weight $\cdot$ day $^{-1}$ ) and to underestimate consumption at high ration levels $\left(>30 \mathrm{cal} \cdot \mathrm{g}^{-1} \cdot \mathrm{day}^{-1}\right.$, equivalent to $>3 \%$ body weight $\cdot \mathrm{day}^{-1}$ ) was indicated for the corrected model (Fig. 2d). Prediction error was indicated to be approximately 6 times lower than for the uncorrected model at corresponding ration levels, and did not exceed $5 \mathrm{cal} \cdot \mathrm{g}^{-1} \cdot \mathrm{day}^{-1}$ (equivalent to $0.5 \%$ body weight $\cdot \mathrm{day}^{-1}$ ).

After correction, the relationship between CRE and temperature also remained significant (Table 5). There was an
Fig. 4. (a) Regression relationships of observed individual white crappie growth rates (GRATE; $\mathrm{cal}^{-1} \mathrm{~g}^{-1} \mathrm{day}^{-1} ; 1 \mathrm{cal}=4.184 \mathrm{~J}$ ) from all laboratory experiments and corresponding mean observed daily

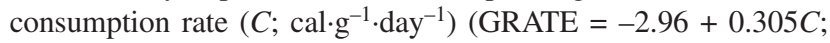
$\left.F_{[1,37]}=833.9, r_{2}=0.95, p<0.0001\right)$. (b) Consumption rate prediction error (CRE; cal. $\mathrm{g}^{-1} \cdot \mathrm{day}^{-1}$ ) of the uncorrected BEM (for individual white crappie) versus corresponding observed growth

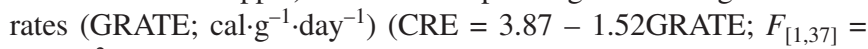
94.8, $\left.r^{2}=0.71, p<0.0001\right)$.
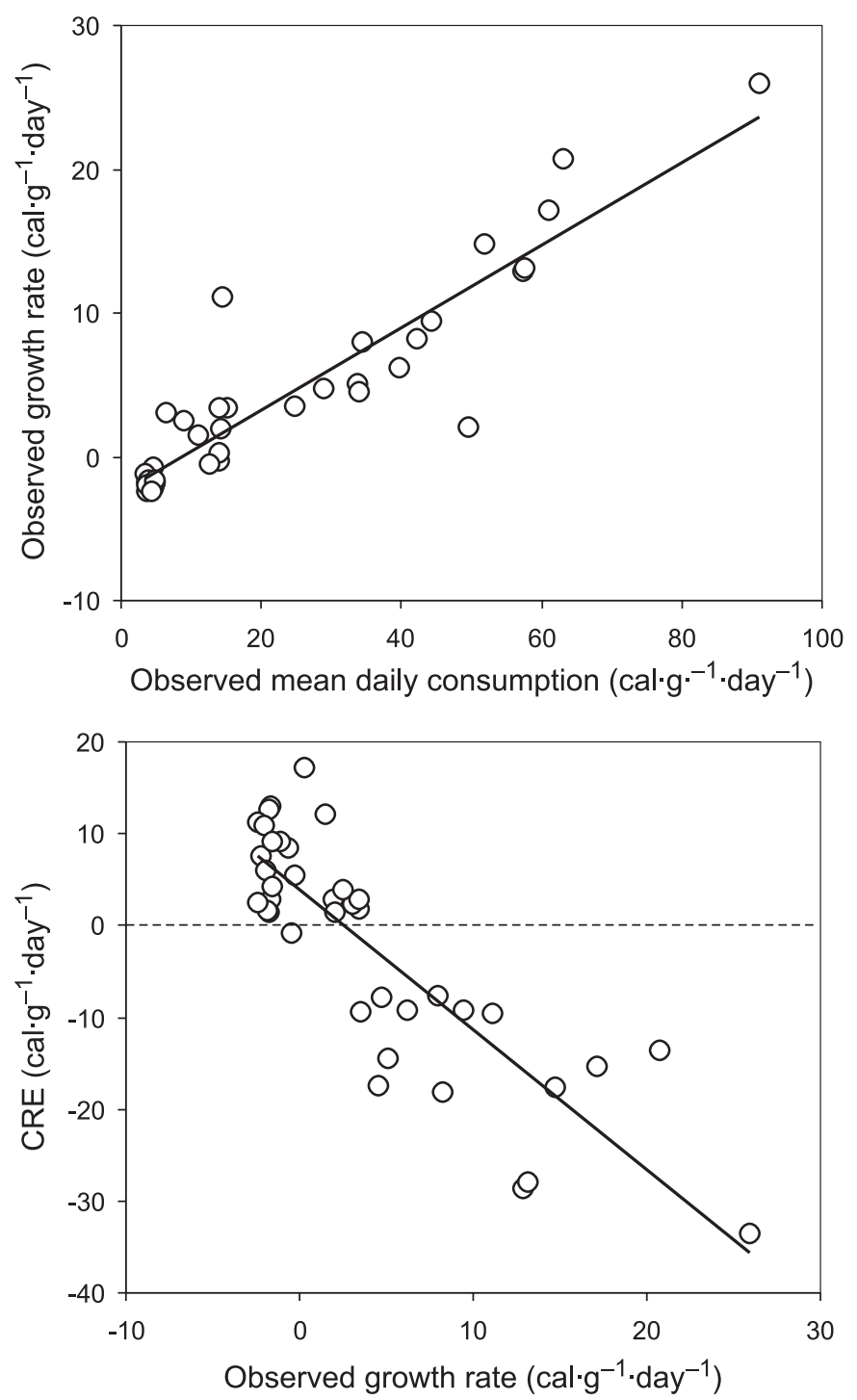

indication that the corrected model would slightly underestimate consumption at the lower end of the tested temperatures $\left(23{ }^{\circ} \mathrm{C}\right)$ and overestimate at the upper end $\left(30^{\circ} \mathrm{C}\right)$. However, the overall error in predicting consumption rate was small and did not exceed $0.2 \%$ body weight $\cdot$ day $^{-1}$ over the range of temperatures evaluated. The overall relationship between $\mathrm{CRE}$ and fish body weight, which was nonsignificant in the uncorrected model, remained so following model correction (Table 5). As for GRE, an indicated strong relationship between CRE and body weight exclusively for fish undergoing weight loss (Fig. 3b) was substantially reduced following correction (Fig. 5b). Although a significant CRE versus body weight 
Table 6. Multiple regression results for response variables growth rate errors (GRE values) and consumption rate errors (CRE values) (both in cal $\cdot \mathrm{g}^{-1} \cdot \mathrm{day}^{-1}: 1 \mathrm{cal}=4.184 \mathrm{~J}$ ) versus mean levels of three predictor variables: consumption level $\left(C ;\right.$ cal $\left.^{-1} \mathrm{~g}^{-1} \cdot \mathrm{day}^{-1}\right)$, fish body weight $(W, \mathrm{~g})$, and temperature $\left(T,{ }^{\circ} \mathrm{C}\right)$.

\begin{tabular}{llll}
\hline Response variable & Predictor variables in model & $R^{2}$ & AIC \\
\hline GRE & $C, T, T \cdot C, T \cdot W, C \cdot W, C \cdot T \cdot W$ & 0.97 & -518.8 \\
GRE & $W, C, T, T \cdot C, C \cdot W, C \cdot T \cdot W$ & 0.97 & -517.6 \\
GRE* & $W, T \cdot C, T \cdot W$ & 0.96 & -517.0 \\
GRE & $C, W, T$ & 0.95 & -506.3 \\
GRE & $C, T$ & 0.80 & -453.0 \\
CRE & $W$, GRATE, $T$ & 0.88 & -431.6 \\
CRE & $W$, GRATE, $T, W \cdot$ GRATE & 0.89 & -430.2 \\
CRE & $W$, GRATE, $T, T \cdot$ GRATE & 0.88 & -430.1 \\
CRE* & GRATE, $W$ & 0.86 & -426.8 \\
CRE & GRATE, $T$ & 0.72 & -399.9 \\
\hline
\end{tabular}

Note: Regression results for the predictor variable growth rate (GRATE; cal $\cdot \mathrm{g}^{-1} \cdot \mathrm{day}^{-1}$ ) were applicable to CRE values only. Values of GRE and CRE and associated mean predictor variables were derived from individual fish for each of the three subperiods of the six laboratory experiments. All possible two- and three-way interactions among the three predictor variables were also considered. The best multiple regression models for GRE and CRE (*) were selected according to Akaike's information criterion (AIC) scores, adjusted $R^{2}$ values, and the number of predictor variables in the model, with more parsimonious models being favored. Selected multiple regression models represent full correction equations that could be incorporated into the uncorrected BEM to improve predictive accuracy.

relationship remained, the biasing effect was relatively minor.

\section{Discussion}

\section{Significance of approach}

Relatively few BEMs have been rigorously evaluated in laboratory settings; however, awareness of the potential to accurately identify model error through laboratory evaluations is growing (e.g., Madenjian and O'Connor 1999; Bajer et al. 2003; Whitledge et al. 2003). Despite findings that internal error exists within BEMs, seemingly logical postevaluation efforts to reduce this error have been rare. We believe that the lack of efforts to improve BEMs is due to to the fact that error sources within these models have remained largely unknown. However, even if likely error sources in these models could be identified, the envisioned set of studies required to improve BEMs' internal subequations may be daunting and without guarantee of success. Recent laboratory evaluations (Madenjian and O'Connor 1999; Bajer et al. 2003) and the present study have identified at least two forms of systematic error within BEMs. Evidence that this systematic error is widespread among BEMs and can cause substantial over- and under-estimation of fish growth and consumption rates (Bajer et al. 2004) heightens the need to improve the predictive accuracy of BEMs, particularly given that rates of application of these models are rapidly increasing.

We have presented a novel and efficient approach for both identifying and correcting systematic error in BEMs that should substantially improve these models' abilities to accurately predict growth and consumption. Correction of systematic error in BEMs is possible, owing to the identification of significant relationships between model prediction error and levels of certain PIO variables (consumption rate, temperature, and fish body weight) for several
BEMs (Bajer et al. 2003, 2004; present study). The correction approach that we present is considered efficient because model error evaluation and correction can be accomplished for a broad array of application conditions from a single laboratory data set that can be generated as a result of a reasonable level of effort.

\section{Model correction versus fundamental improvement}

Although we believe that development of correction equations offers an efficient and effective means for reducing potentially important systematic error in individual BEMs, model correction is not intended to fully substitute for the development of sound BEMs. Models that are fundamentally sound should perform better than those that incorporate correction equations. Accordingly, our error-correction approach is not intended to promote "rough-cut" construction of new BEMs, where developers might plan to counter expected inaccuracies by subsequently applying correction equations. Nor should our correction approach discourage in-depth efforts to fundamentally improve existing BEMs, such as by developing more complete and accurate internal equations for calculating energy costs and losses.

The findings of Bajer et al. (2004) indicate that all BEMs should be assumed to contain systematic error that could result in important inaccuracies whenever they are applied. Consequently, we suggest that error correction should be considered for any BEM when there are near-term plans for its application and the model has not been either fundamentally improved (e.g., via reevaluation and improvement of internal subequations) or corrected under the ranges of consumption level, fish body weight, and temperature to which it will be applied. Although prediction error in BEMs may be greatest under conditions where fish experience high consumption and growth rates (Bajer et al. 2004), we caution against using unimproved or uncorrected BEMs when high consumption and growth conditions are not anticipated in 
Fig. 5. (a) Before- (O) and after-correction $(\bigcirc)$ regression relationships of BEM growth rate prediction errors (GRE) versus mean body weights of individual white crappie over modeled intervals. (b) Similarly for consumption rate prediction error (CRE) versus mean body weights. For both GRE and CRE, regression slopes and intercepts were significantly closer to zero following correction of the BEM (slope differences were determined by heterogeneity of slopes tests at $p \leq 0.05$, one-tailed test; intercepts were considered to differ if intercept means \pm 2 SEs did not overlap). $1 \mathrm{cal}=4.184 \mathrm{~J}$.
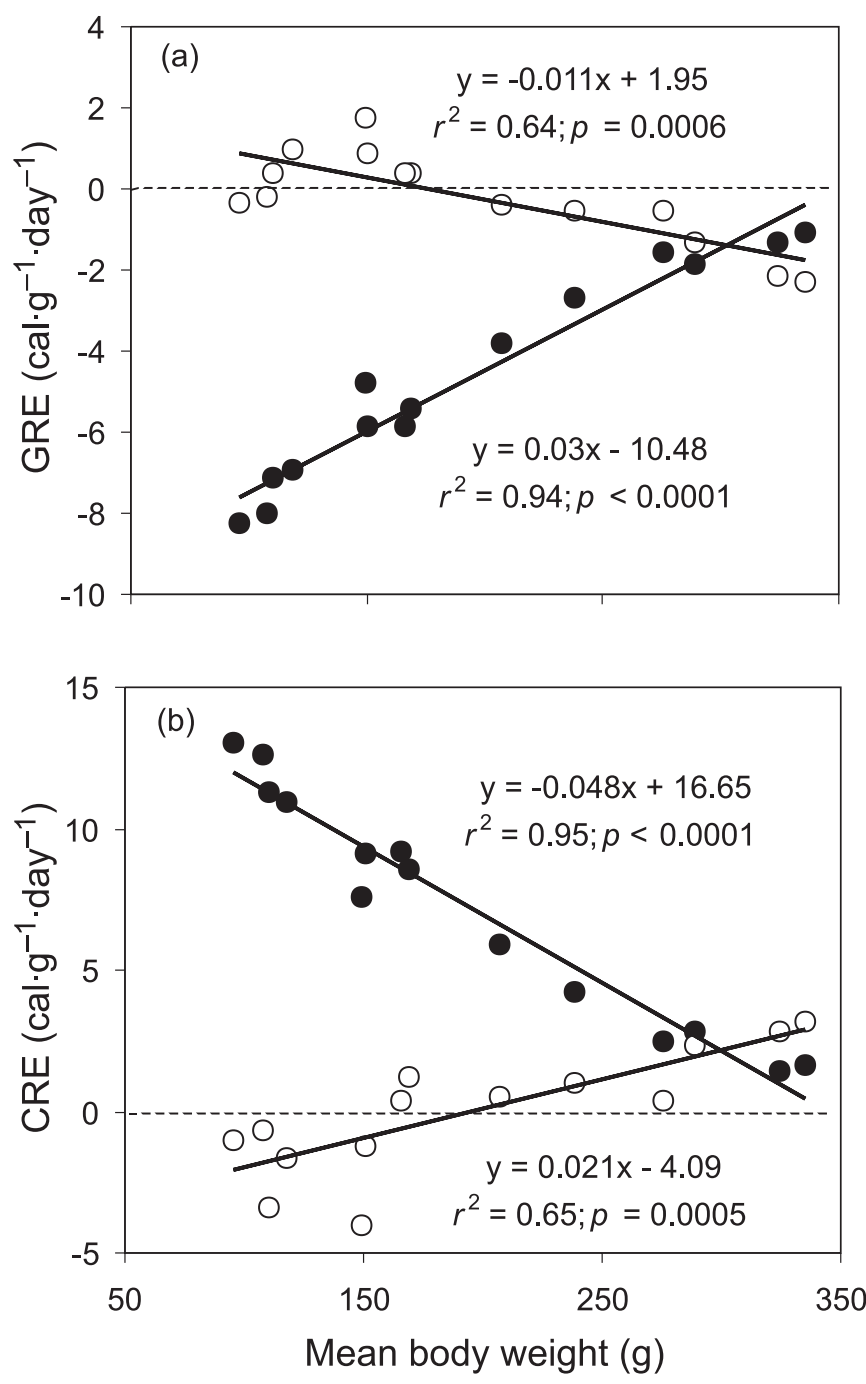

the application setting. Such conditions are difficult to anticipate, particularly in field settings, and it has been demonstrated that even short episodes of higher consumption or growth rates can lead to substantial prediction error.

\section{Facilitating fundamental improvement of BEMs}

The initial steps of developing correction equations for BEMs can also facilitate efforts to fundamentally improve these models. Defined correlations between model prediction error and certain PIO variables (necessary for model correction) indicate which energy cost/loss parameters within a BEM $\left(R_{\mathrm{s}}, \mathrm{ACT}, \mathrm{SDA}, F\right.$, and $\left.U\right)$ are likely sources of systematic error. Consumption level was highly correlated with prediction error in the uncorrected white crappie model, and it follows that one or more of the consumption-dependent cost/loss parameters in the uncorrected white crappie model (SDA, $F$, and $U$; eqs. 5-7) were likely sources of the observed systematic error. That a strong correlation has been found between consumption level and prediction error in a substantial number of BEMs (Madenjian and O'Connor 1999; Bajer et al. 2003, 2004) suggests inaccuracies in the equations for calculating SDA, $F$, or $U$ in many BEMs. Another potential source of the observed consumptiondependent systematic error in BEMs could be unaccountedfor feeding-activity costs that are independent of SDA, and may involve feeding and foraging activity (Brett and Groves 1979; Cui and Wootton 1989) that increases with consumption level. A more detailed consideration of likely sources of the consumption-dependent systematic error within BEMs is provided by Bajer et al. (2004).

Although an overall relationship between model prediction error and fish body weight was not observed for the uncorrected white crappie model, a strong correlation was found when the analysis was restricted to fish from experiments 2 and 3 that were losing weight. Under these conditions, the uncorrected model underestimated growth rates of white crappie and overestimated their consumption rates. Growth and consumption prediction error increased with decreasing fish weight, accounting for the correlation between model prediction error rate and fish body weight. Inadequacy of the equation for routine standard metabolism $\left(R_{\mathrm{s}}\right)$ was indicated as the source of this error because it is the only energy cost/loss term in the uncorrected model with body-weight dependence. Hence, the correlation between model prediction error rate and fish body weight indicates that calculated $R_{\mathrm{S}}$ values were generally too high for fish undergoing weight loss and that overcalculation of metabolic cost increased for fish of lesser body weight. Reduction of metabolic rates in fish experiencing submaintenance feeding conditions is reasonably well documented (Beamish 1964; Glass 1968; O'Connor et al. 2000). However, this energy-conserving metabolic response is not included in most BEMs even though these models are sometimes applied to fish losing weight.

The uncorrected white crappie BEM was not originally designed to accommodate fish undergoing weight loss, and rigorous evaluation using data from experiments 2 and 3 revealed that it estimated consumption rates particularly poorly under these conditions. However, correction of the model using a data set that included some fish subjected to submaintenance feeding caused it to perform quite well under weight-loss conditions. Hence, a capacity was demonstrated for the correction procedure to extend a BEM's predictive ability beyond the bounds within which it was originally constructed.

\section{Applying the corrected model}

Cross-validation results indicated that the corrected BEM would provide substantially better predictions of white crappie growth and consumption than the uncorrected model when applied within the bounds of consumption level, body weight, and temperature covered by our six laboratory experiments. However, the set of error-correction equations that we developed were derived under all conditions present in our laboratory growth experiments, not only those of the three PIO variables. Consequently, even when white crappie experience consumption levels, temperatures, and body weights in other application settings that are within those bounded by our six laboratory ex- 
periments, the correction equations that we present could be suboptimal, a possibility not fully reflected by our crossvalidation results. In particular, substantial differences in white crappie activity levels or prey types, relative to those of the underlying laboratory experiments, could conceivably affect the extent to which our correction equations are optimal.

Through modeling, however, we were able to gain insight into the extent to which differences in fish activity level over time and locations would affect the applicability of the correction equations that we developed for the white crappie BEM through laboratory evaluations. First, using the uncorrected white crappie model, we entered the same initial fish weight $(100 \mathrm{~g})$, temperature $\left(27^{\circ} \mathrm{C}\right)$, and activity level $(\mathrm{ACT}=1)$ in five single-time-step model runs, each run differing only in consumption level $\left(0,20,40,60\right.$, and $\left.80 \mathrm{cal} \cdot \mathrm{g}^{-1}\right)$; the resulting five model outputs of relative growth rate (RGR) increased linearly with consumption level (Fig. 6). We repeated these five simulations but with the corrected model. As expected, the resulting line of RGR values from the corrected model transected the corresponding line from the uncorrected model, the RGR values from the corrected model being lower at high consumption and higher at low consumption, reflecting correction of consumption-dependent model error (Fig. 6). The area between these two lines represented the estimated growth prediction error from the uncorrected model. The critical result was that when we ran the same simulations again with the two models, but using a substantially increased activity level $(\mathrm{ACT}=3)$, the relationship between the RGR lines versus consumption level from the two models remained identical, even though both lines were shifted substantially downward because of the tripling of activity cost. Thus, prediction error (the area between the two lines) was uninfluenced by the marked change in activity level, so the same correction equation developed under one activity level will be appropriate at other activity levels. It is assumed, of course, that appropriate activity levels will be entered for all BEM simulations.

When developing the multiple regression equation for correcting the white crappie model's estimates of consumption, we used GRATE as a necessary surrogate for the input variable, consumption level. However, in BEM application settings where fish activity cost is substantially greater than that assumed in our laboratory experiments (zero activity cost), the relationship that we derived to estimate CRE values and correct consumption estimate error will be less appropriate. This relates to the fact that fish growth rates will decline with increasing activity (Fig. 6), causing the relationship between GRATE and CRE to be different from that which we originally observed across the laboratory experiments. However, in these other settings the relationship between total energy allocated to growth and activity (EGA = growth rate + activity, both in cal $\cdot \mathrm{g}^{-1} \cdot \mathrm{day}^{-1}$ ) versus CRE will remain the same as we determined in the laboratory. Thus, in application settings with substantially different fish activity costs, our correction equation for consumption (eq. 14) will be appropriate if GRATE is replaced by EGA. Again, this will require that fish activity cost be known over modeling intervals, but rightfully, activity levels should be determined even when uncorrected models are used.

We were unable to assess the extent to which differences in prey types would influence the appropriateness of the cor-
Fig. 6. Relative growth rates predicted by the uncorrected (broken lines) and corrected (solid lines) white crappie BEM for a 100 -g fish at $27{ }^{\circ} \mathrm{C}$ and five different consumption levels. Predictions were generated for two levels of fish activity: ACT $=1$ represents no activity cost above resting routine metabolism; $\mathrm{ACT}=3$ represents an activity cost that is three times resting routine metabolism. The areas between the solid and broken lines represent the prediction error, which does not change over the two activity levels. $1 \mathrm{cal}=4.184 \mathrm{~J}$.

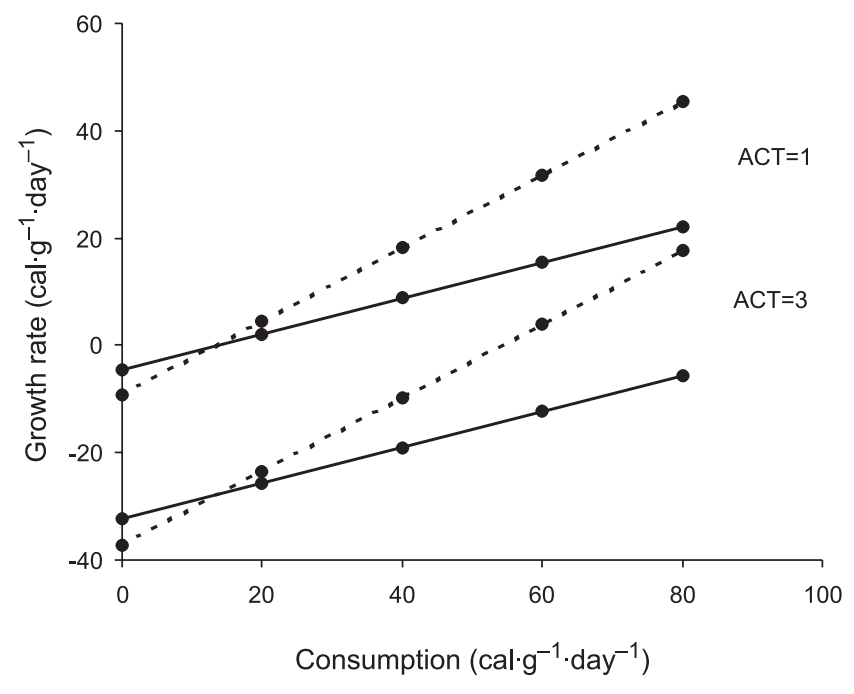

rection equations that we developed for the white crappie BEM, because only one prey type (fathead minnow) was used in the six laboratory experiments. However, we do feel that potential influences of differing prey types on the appropriateness of the presented set of BEM correction equations should be investigated. Although small fish often represent major portions of white crappie diets, this is not always so. We urge prospective users of the white crappie BEM to conduct what should be simple laboratory experiments to determine whether the corrected BEM performs as well for white crappie consuming an alternative prey type of interest as it does for white crappie consuming fathead minnows. We have presented a novel approach for reducing recently identified important error in BEMs. Efforts from other users of BEMs will be required to evaluate and further develop this approach

\section{Designing laboratory experiments for correcting BEMs}

The process of collecting data for evaluating BEMs has been considered difficult, and may account for the fact that rigorous evaluations have lagged well behind model application rates (Hewett and Johnson 1987). This view could apply to the process of constructing correction equations for BEMs, because development of a model-evaluation data set is the initial step. However, we believe that data sets for BEM evaluations, including those covering broad ranges of growth conditions, can be developed with reasonable effort if certain efficiency measures are incorporated into experimental designs. Fundamentally, a data set for evaluating a BEM will consist of observed growth rates for fish of a range of body weights experiencing known ranges of daily consumption level and temperature. Also needed are known or reasonably estimated values of activity cost and caloric density for test 
fish and their prey. We recommend laboratory over field experiments for developing correction equations because the conditions that fish must experience to produce observed growth can be more accurately determined. Using individually held fish versus fish groups as the sample unit (as in the present study) allows substantially more observations per area of laboratory space and tends to improve statistical power. Holding fish individually also eliminates social interaction among them, which can be problematic in terms of its effects on food consumption and activity.

The use of full factorial experimental designs is desirable and may be feasible, particularly when using individually held fish. If possible, each of the three BEM input/output variables (consumption level, body weight, and temperature) should be represented at a minimum of three levels that span the full ranges of these conditions in anticipated BEM application settings. A full factorial design with three factors represented at three levels would involve 27 treatments, each with a distinct combination of consumption level, body weight, and temperature. We suggest that at least four fish be assigned to each treatment to reduce within-treatment variance. Full factorial designs promote a clearer interpretation of the determined predictive error because the applied variables are uncorrelated and allow for the subsequent construction of robust correction equations. Alternatively, less space-demanding fractional factorial designs, such as the one used in the present study, can provide good descriptions of systematic error in BEMs if sufficient portions of the array of consumption levels, body weights, and temperatures are covered.

Growth experiments need only be run long enough to establish a fish's growth pattern under a given set of conditions; 20-day experiments are recommended, where body weights are measured at the start and finish of this interval, consumption is measured daily, and temperature is constant. Longer experiments contribute no additional information in evaluation and correction data sets while substantially increasing costs. Short experiment periods also tend to involve more constant sets of growth conditions, which is desirable when analyzing associations between model error rate and associated consumption levels, body weights, and temperatures.

\section{Acknowledgements}

Funding for this work was provided in part by research grants to R.S. Hayward from the Missouri Department of Conservation. These grants provided graduate research assistantship (GRA) funding for P.G. Bajer and R.D. Zweifel. We thank James Breck for insights and helpful suggestions relating to many aspects of this study, and Marc Trudel for a thorough review of the manuscript.

\section{References}

Allen, J.R.M., and Wootton, R.J. 1982. The effect of ration and temperature on the growth rates of the three-spined stickleback (Gasterosteus aculeatus L.). J. Fish Biol. 20: 409-422.

Bajer, P.G., Whitledge, G.W., Hayward, R.S., and Zweifel, R.D. 2003. Laboratory evaluation of two bioenergetics models ap- plied to yellow perch (Perca fluviatilis): identification of a major source of systematic error. J. Fish Biol. 62: 436-454.

Bajer, P.G., Whitledge, G.W., and Hayward, R.S. 2004. Widespread consumption-dependent systematic error in fish bioenergetics models and its implications. Can. J. Fish. Aquat. Sci. 61. This issue.

Beamish, F.W.H. 1964. Influence of starvation on standard and routine oxygen consumption. Trans. Am. Fish Soc. 93: 103-107.

Brett, J.R., and Groves, D.D. 1979. Feeding metabolism. In Fish physiology. Vol. 8. Bioenergetics and growth. Edited by W.S. Hoar, D.J. Randall, and J.R. Brett. Academic Press, New York. pp. 298-305.

Burnham, K.P., and Anderson, D.R. 2001. Kullback-Leibler information as a basis for strong inference in ecological studies. Wildl. Res. 28: 111-119.

Carline, R.F., and Hall, D.J. 1973. Evaluation of a method for estimating food consumption rates of fish. J. Fish. Res. Board Can. 30: 623-629.

Cui, Y., and Wootton, R.J. 1989. Bioenergetics of growth of a cyprinid, Phoxinus phoxinus (L.): development and testing of a growth model. J. Fish Biol. 34: 47-64.

Davis, G.E., and Warren, C.E. 1971. Estimation of food consumption rates. In Methods for assessment of fish production in fresh waters. Edited by W.E. Ricker. Blackwell Scientific Publications, Oxford. pp. 227-248.

Glass, N.R. 1968. The effect of time of food deprivation on the routine oxygen consumption of largemouth bass (Micropterus salmonides). Ecology, 49: 340-343.

Hanson, P.C., Johnson, T.B., Schindler, D.E., and Kitchell, J.F. 1997. Fish bioenergetics 3.0. University of Wisconsin Sea Grant Institute, Madison.

Hewett, S.W., and Johnson, B.L. 1987. A generalized bioenergetics model of fish growth for microcomputers. Sea Grant Tech. Rep. No. WISCG-87-245, University of Wisconsin, Madison.

Hewett, S.W., and Johnson, B.L. 1992. Fish bioenergetics model 2: an upgrade of a generalized bioenergetics model of fish growth for microcomputers. University of Wisconsin Sea Grant Institute, Madison.

Jobling, M. 1994. Fish bioenergetics. Chapman and Hall, London.

Kitchell, J.F., Stewart, D.J., and Weininger, D. 1977. Applications of a bioenergetics model to yellow perch (Perca flavescens) and walleye (Stizostedion vitreum). J. Fish. Res. Board Can. 34: 1922-1935.

Madenjian, C.P., and O'Connor, D.V. 1999. Laboratory evaluation of a lake trout bioenergetics model. Trans. Am. Fish. Soc. 128: 802-814.

Neter, J., Kutner, M.H., Nachtsheim, C.J., and Wasserman, W. 1996. Applied linear statistical models. 4th ed. The McGrawHill Companies Inc., New York.

Ney, J.J. 1999. Pratical use of biological statistics. In Inland fisheries management in North America. Edited by C.C. Kohler and W.A. Hubert. American Fisheries Society, Bethesda, Md. pp. 167-191.

O'Connor, K.I., Taylor, A.C., and Metcalfe, N.B. 2000. The stability of standard metabolic rate during a period of food deprivation in juvenile Atlantic salmon. J. Fish Biol. 57: 41-51.

Whitledge, G.W., Hayward, R.S., Zweifel, R.D., and Rabeni, C.F. 2003. Development and laboratory evaluation of a bioenergetics model for sub-adult and adult smallmouth bass. Trans. Am. Fish. Soc. 132: 316-325.

Zweifel, R.D. 2000. Development and evaluation of a bioenergetics model for white crappie. M.Sc. thesis, University of Missouri, Columbia. 